\title{
Role of Diffusion Tensor Imaging in Detection and Lateralization of Temporal Lobe Epilepsy
}

\author{
NERMEEN M.S. GARHY, M.D.*; AMR O.M.A. AZAB, M.D.*; RANIA Z. HASSAN, M.D.* and \\ ASMAA M. EBRAHEIM, M.D.** \\ The Departments of Radiology* and Neurology**, Faculty of Medicine, Cairo University
}

\begin{abstract}
Background: Temporal lobe epilepsy (TLE) is the most common localization related epilepsy syndrome. Diffusion tensor imaging (DTI) is a new imaging technique that is sensitive to the structural integrity changes of cerebral tissue in patients with TLE who have been evaluated for epilepsy surgery.
\end{abstract}

Aim of Study: To demonstrate the role of diffusion tensor imaging in the diagnosis of temporal lobe epilepsy.

Patients and Methods: This is a prospective study included 40 patients diagnosed clinically as having TLE and twenty control subjects. The patients and control groups are examined by conventional magnetic resonance imaging (MRI) followed by DTI and tractography. EEG examination, was performed to 36 patients only, the remaining 4 were missed during followup. It was done to support the clinical diagnosis of TLE and to help in the lateralization of the site of seizure focus to be compared with DTI results.

Results: The calculated cut off value regarding fractional anisotropy (FA )difference between both hippocampi was 0.014 . Twenty eight patients with FA differences above this value were considered as DTI positive of hippocampal abnormality and 12 patients were below this value and were considered as DTI negative. FA differences between both hippocampi in patients' group were significantly increased as compared with the control group.

Conclusion: DTI can detect hippocampal abnormalities even in patients with normal conventional MR, so it can be used to lateralize seizure side, thus increase the diagnostic accuracy before epilepsy surgery.

Key Words: Diffusion - Hippocampus - Epilepsy - Fractional anisotropy.

\section{Introduction}

TEMPORAL lobe epilepsy (TLE) is the most common localization related epilepsy syndrome

Correspondence to: Dr. Nermeen M.S. Garhy,

The Department of Radiology, Faculty of Medicine,

Cairo University and is often unresponsive to medical therapy. Mesial temporal sclerosis (MTS) is the most commonly observed pathology in TLE [1]

The ultimate goal of neuro imaging of epilepsy is not only detection of epileptogenic lesions but also to confirm lateralization of the seizure activity, to plan for a potential surgery as well as to provide information on etiology and patho-physiologic mechanism. These goals make a potential value for new structural magnetic resonance neuro imaging techniques such as diffusion tensor imaging [2].

Diffusion tensor imaging is a novel imaging technique that provides insight into the structural integrity of cerebral white matter through the measurement of water diffusion [3] .

The major limitation of conventional MRI in patients with TLE is the fact that MRl studies can be completely normal in those patients. By contrast, diffusion tensor imaging (DTl) is sensitive to physiological changes that take place in the brain tissue ictally and interictally [4]

\section{Patients and Methods}

This study was conducted in Radio-Diagnosis Department, Faculty of Medicine, Cairo University between January 2013 and December 2014. The study included 40 TLE patients including 17 Males and 23 Females, referred from neurology department and outpatient clinic. Twenty healthy individuals selected from patients relatives were assessed as a control group.

Inclusion criteria: All patients were diagnosed as having TLE with or without secondary general- 
ization clinically. The patients were either newly diagnosed untreated or treated temporal lobe epileptics.

Exclusion criteria: Patients with other types of epilepsy partial or generalized epilepsy or patients with co-morbidity either medical or neurological disorders.

EEG examination, was performed to 36 patients only, the remaining 4 were missed during follow-up. It was done to support the clinical diagnosis of TLE and to help in the lateralization of the site of seizure focus to be compared with DTI results.

MR examination included non contrast conventional axial T1WI, coronal T2WI and coronal FLAIR on temporal lobe and Diffusion Tensor Imaging medium.

Technique was performed using a standard 1.5 Tesla unit (Intera and Achiva, Philips).

Head coils were used (NV16 for Intera and NV8 and NV 16 for Achiva).

\section{Imaging parameters:}

Axial T1WI: TR 450ms, TE $15 \mathrm{~ms}$, Flip $69^{\circ}$, Matrix 180x169, FOV (field of view) 210x236, Number of excitation: 2, Slice thickness: 6.0/1.5.

Coronal T2WI on temporal lobe: TR 2.2s, TE $100 \mathrm{~ms}$, Flip angle $90^{\circ}$, FOV $200 \mathrm{~mm}$, Slice thickness: $4.0 /-0.01$.

Coronal FLAIR on temporal lobe: TR 8.0s, TE $125 \mathrm{~ms}$, Flip angle $90^{\circ}$, FOV $200 \mathrm{~mm}$, Slice thickness: $4.0 /-0.01$.

Diffusion Tensor consisted of: A single shot, spin-echo echo planar sequence in 12 encoding directions, diffusion weighting factor of $800 \mathrm{~s} /$ $\mathrm{mm}^{2}$, TR $8000 \mathrm{~ms}$, TE $67 \mathrm{~ms}$, flip $90^{\circ}$, matrix 112 x 110, FOV 210 x $236 \mathrm{~mm}$, number of excitations: 2, slice thickness: $2.0 / 00$.

\section{Case 1:}

- Clinical data: Male patient, 40 years old, presented with seizure started when he was 1 year old. $\mathrm{He}$ was diagnosed as having temporal lobe epilepsy mainly clinically.

- EEG: Revealed fronto temporal epileptogenic dysfunction.

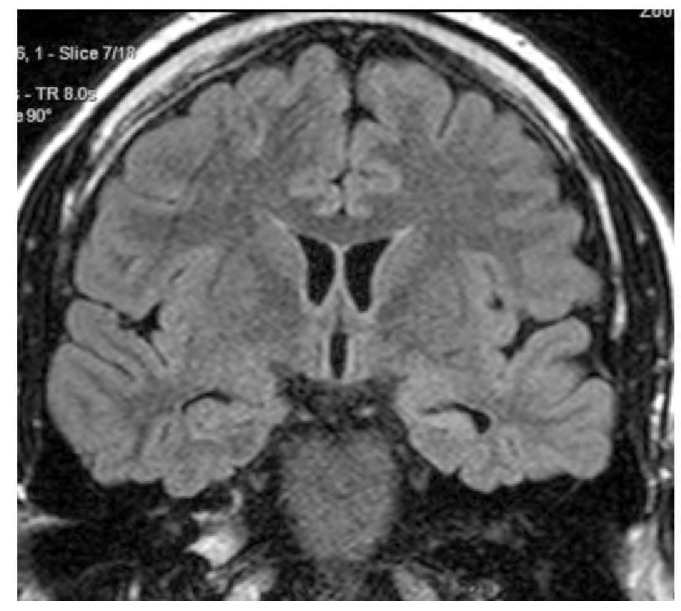

Fig. (1): Coronal FLAIR image at the level of hippocampal head showed signs of left hippocampal sclerosis in the form of: Small sized left hippocampus as compared with the right side with prominent ipsi lateral temporal horn.

\section{Post processing DTI images:}

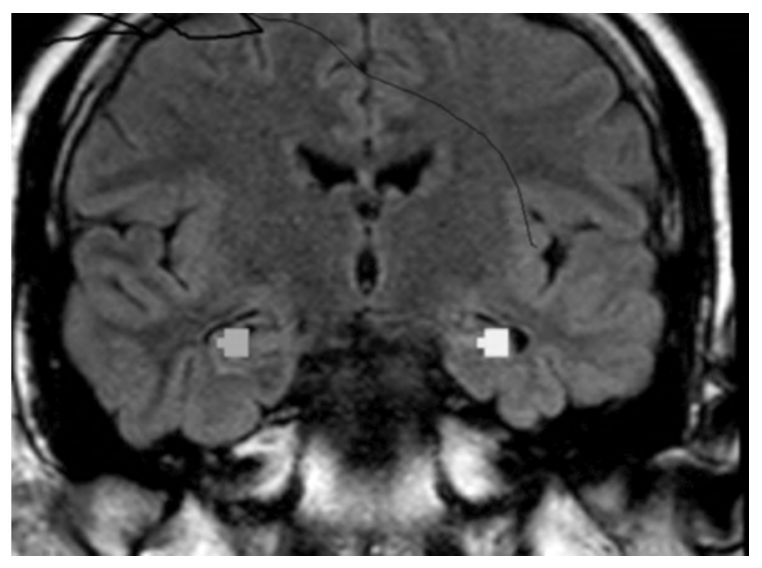

Fig. (2): FA was measured by drawing ROI at the level of hippocampal head in coronal FLAIR image with the same number of voxels bilaterally and revealed that FA of LT hippocampus was 0.16 and of RT hippocampus was 0.31 , FA difference between them was 0.15 .

Case 2:

- Clinical data: Male patient, 29 years old, presented with seizures started when he was 19 years old. He was diagnosed clinically as having temporal lobe epilepsy.

- EEG: Revealed bi fronto temporal shifting lateralization with left side predominance. 

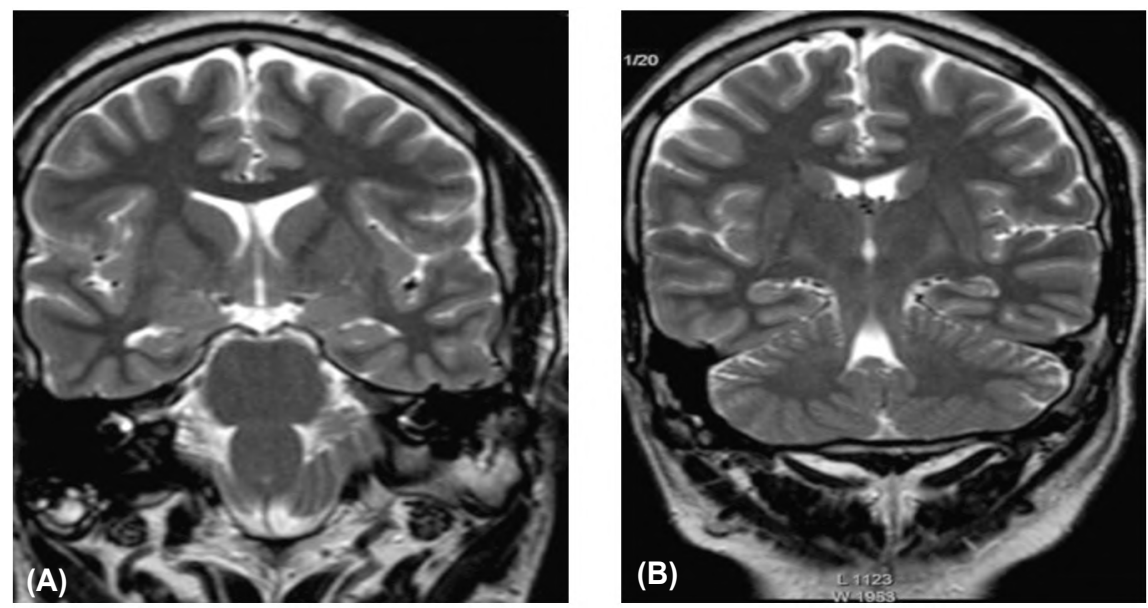

Fig. (3): Coronal T2WI (A) at the level of hippocampal head (B) at the level of hippocampal tail showed normal appearance of both hippocampi.

Post processing DTI images:

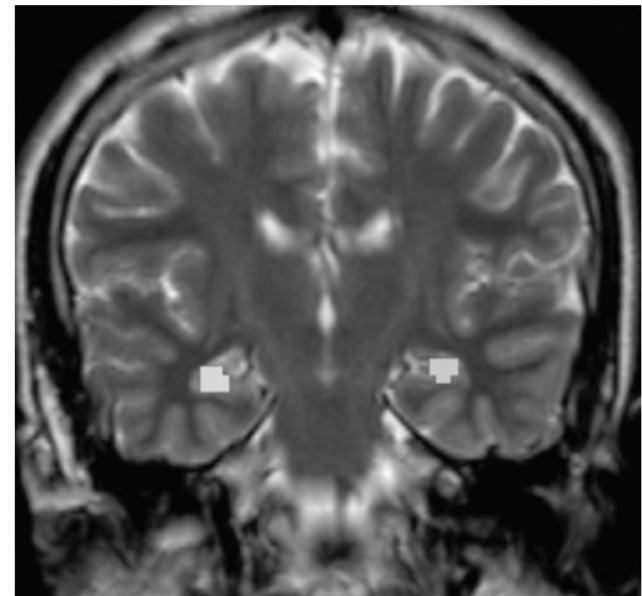

Fig. (4): FA was measured by drawing ROI at the level of hippocampal head in coronal T2WI with the same number of voxels bilaterally and revealed that FA of LT hippocampus (violet) was 0.359 and of RT hippocampus (orange) was 0.347 ; FA difference between both sides was 0.012 .

\section{Results}

Diagnostic indices of FA differences between both hippocampi in patients and control groups using ROC curve is summarized in (Table 1).

Table (1): Diagnostic indices of FA differences between both hippocampi in patients and control groups using ROC curve.

\begin{tabular}{lc}
\hline & $\begin{array}{c}\text { FA difference between } \\
\text { both hippocampi }\end{array}$ \\
\hline Area under the roc & 0.886 \\
Cut off & $>0.014$ \\
Sensitivity & 70 \\
Specificity & 100 \\
Positive predictive value & 100 \\
Negative predictive value & 62.5 \\
\hline
\end{tabular}

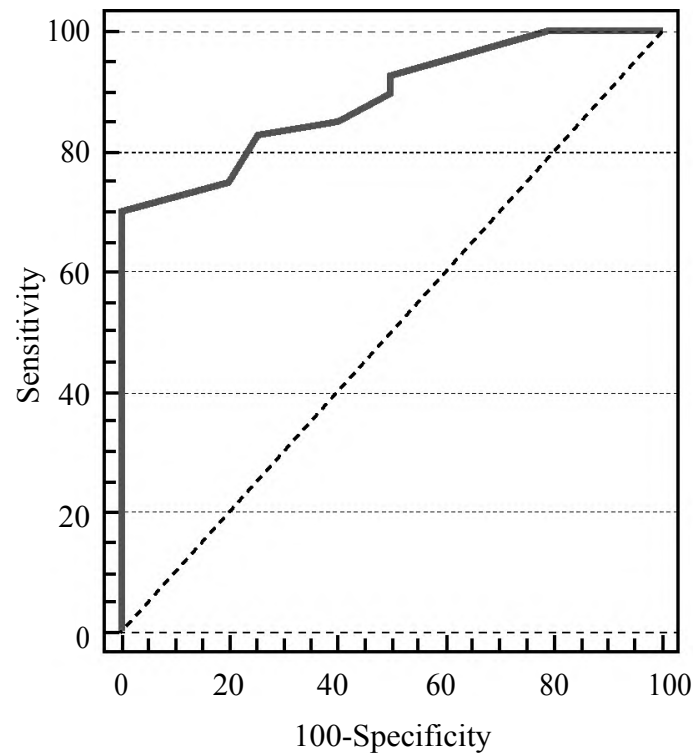

Fig. (5): ROC curve of FA differences between both hippocampi.

The calculated cut off value regarding FA difference between both hippocampi was 0.014 . Twenty eight patients with FA differences above this value were considered as DTI positive of hippocampal abnormality and 12 patients were below this value and were considered as DTI negative.

We assessed the significance of FA reduction in detection of hippocampal abnormalities through comparing the mean FA difference in patients with positive DTI findings with mean FA difference in the control group. We found that FA differences between both hippocampi in patients' group were significantly increased as compared with the healthy group (Table 2). 
Table (2): Comparison between the mean of FA differences between both hippocampi in patients' group with positive DTI findings $(\mathrm{n}=28)$ and the control group $(n=20)$.

\begin{tabular}{lccc}
\hline & $\begin{array}{c}\text { Control group } \\
(\mathrm{n}=20)\end{array}$ & $\begin{array}{c}\text { Positive cases } \\
\text { in patients } \\
(\mathrm{n}=28)\end{array}$ & $p$-value \\
\hline Mean $\pm \mathrm{SD}$ & $0.009 \pm 0.004$ & $0.063 \pm 0.039$ & $0.001^{* *}$ \\
\hline$* * p<0.01=$ Highly significant. &
\end{tabular}

By comparing DTI findings with MR findings we found that: Of MR negative patients 12 patients $(54.5 \%)$ were DTI negative and $10(45.5 \%)$ were positive and of MR positive patients $100 \%$ were DTI positive and $0 \%$ were DTI negative. This means that DTI could detect hippocampal abnormality in patients with negative MR findings (Table $3)$.

Table (3): Comparison between DTI and MR findings.

\begin{tabular}{lcc}
\hline DTI findings & \multicolumn{1}{c}{ MR findings } \\
\hline Positive & 28 & $\begin{array}{l}\text { 18 of positive cases in DTI were } \\
\text { positive in MR } \\
\end{array}$ \\
& & $\begin{array}{l}\text { 10 of positive cases in DTI were } \\
\text { negative in MR }\end{array}$ \\
Negative & 12 & $\begin{array}{l}\text { All of } 12 \text { negative cases in DTI } \\
\text { were negative in MR }\end{array}$ \\
\hline Total & 40 & \\
\hline
\end{tabular}

Focal EEG findings (the epileptic focus at right or left temporal lobe) were present in 10 patients. This focus was matched to that demonstrated by DTI in 6 patients, and was at a different side in 4 patients (Table 4).

Table (4): Site of lateralization of epileptic focus demonstrated by EEG weather matched or not with that demonstrated by DTI.

\begin{tabular}{ccc}
\hline $\begin{array}{l}\text { Focal EEG result } \\
\text { (right or left) }\end{array}$ & $\begin{array}{c}\text { Matching } \\
\text { with DTI }\end{array}$ & $\begin{array}{c}\text { Not Matching } \\
\text { with DTI }\end{array}$ \\
\hline 10 & $6(60 \%)$ & $4(40 \%)$ \\
\hline
\end{tabular}

\section{Discussion}

The hippocampus is an essential structure in the epileptogenicity of TLE, and hippocampal sclerosis is the main pathology underlying non lesional TLE. Hippocampal atrophy on brain MR images is not always indicative of epileptogenicity [5].

In this study, we investigated the role of DTI measurement (FA) in detection of mesial temporal sclerosis in patients with normal conventional MR and probe its role in lateralization of seizure focus in correlation to EEG. The FA difference between both hippocampi reported inpatients as compared with values in the control group, serving as a lateralizing evidence of the epileptogenic hippocampus to the side of reduced FA. These findings match with the results reported by Assafa et al., 2003 [5] in TLE patients.

FA differences between both hippocampi in patients' group with positive DTI findings were significantly decreased as compared with the healthy group. Studying the association between the side of seizure focus demonstrated by DTI versus EEG lateralization, we found that: Among 10 patients having focal EEG findings; 6 of them $(60 \%)$ were matched with DTI findings and 4 $(40 \%)$ were not matched with DTI. This could be due to the false lateralization by EEG which has been reported in previous studies [6,7]. This was explained by the failure of ictal activity to propagate in the ipsilateral temporal lobe but strongly propagated to the contra lateral temporal lobe.

In conclusion: DTI is a new structural imaging technique that can help in assessment of temporal lobe epilepsy patients to early detect and lateralize hippocampal abnormalities particularly in patients with no gross abnormalities in conventional MRI.

\section{References}

1- CONCHA L., DANIEL J.L., BEAULIEU C., et al.: In vivo diffusion tensor imaging and histopathology of fimbria-fornix in temporal lobe epilepsy. Journal of Neuroscience, 30 (3): 996-1002, 2010.

2- SALEEM S. and SAID A.H.: Role of diffusion tensor Imaging in management of epileptic patients with focal brain lesions. The Egyptian journal of Radiology and Nuc. Med., 39 (1): 269-278, ,2008.

3- DONALD W.G.: Diffusion tensor imaging in temporal lobe epilepsy. epilepsia, 52 (Suppl. 4): 32-34, 2011.

4- LIACU D., IDY-PERETTI I., DUCREUX D., et al.: Diffusion tensor imaging tractography parameters of limbic system bundles in temporal lobe epilepsy patients. Journal of Magnetic Resonance Imaging, 36: 561-568, 2012.

5- ASSAFA B.A., MOHAMED F.B., ABOU-KHALEDA K.J., et al. Diffusion tensor imaging of the hippocampal formation in temporal lobe epilepsy. AJNR, 24: 1857 $1862,2003$.

6- ADAMOLEKUN B., AFRA P. and BOOP F.A.: False lateralization of seizure onset by scalp EEG in neocortical temporal lobe epilepsy. Seizure, Jul., 20 (6): 494-9, 2011.

7- SAMMARITANO M., de LOTBINIERE A., ANDERMANN F., et al.: False lateralization by surface EEG of seizure onset in patients with temporal lobe epilepsy and gross focal cerebral lesions. Ann. Neurol. Apr., 21 (4): 361-9, 1987. 


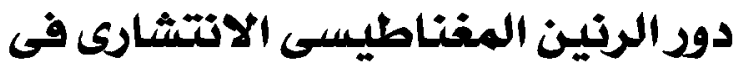

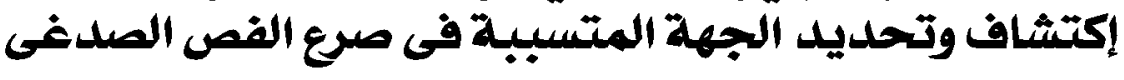

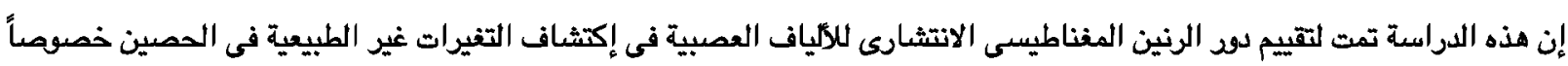

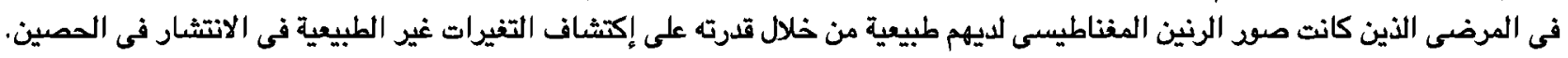

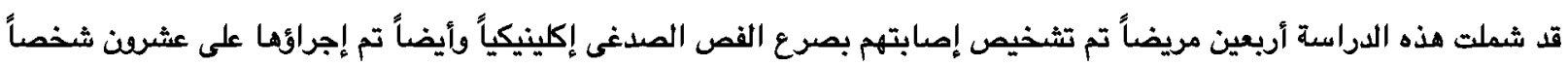

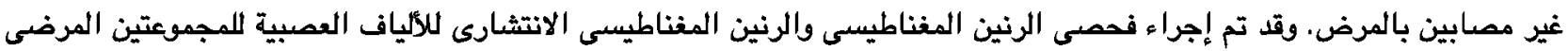
والأصحاء.

كما قد تم أجراء رسم مخ لستة وثلاثين مريضاً فقط حيث أن الأربعة الآخرين فقدوا خلال فترة المتابعة.

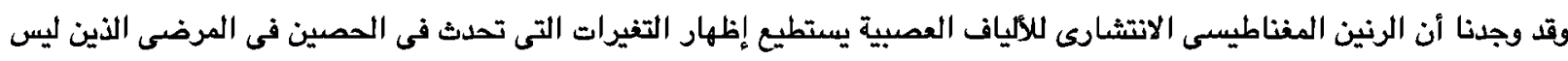

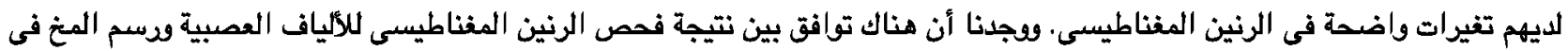
ستون بالمائة من المرضى الذين أظهرت نتيجة فحص رسم المخخ بالنسبة لهم أن هناك مكان محدد اللبؤدة الصرعية. 